\title{
Centralised Order Books versus Hybrid Order Books: \\ A Paired Comparison of Trading Costs on NSC (Euronext Paris) and SETS (London Stock Exchange)*
}

Jean-François Gajewski

University of Paris 12 - Val de Marne, IRG

e-mail: gajewski@univ-paris12.fr

Carole Gresse ${ }^{\wedge}$

Paris-10-Nanterre University, CEROS

\& Paris-Dauphine University, CEREG

e-mail: carole.gresse@u-paris10.fr

http://www.carolegresse.com

JEL classification: G19

Keywords: $\quad$ transaction costs, spread components, order books, hybrid markets, centralised markets, fragmentation

This draft: May 2004

\footnotetext{
* We are grateful to Erik Theissen, Laurie Prather and participants at the 2003 EFMA meetings and the 2003 MFS conference for helpful comments. The data from the London Stock Exchange was provided by the CEREG (Paris-Dauphine University) and the data from Euronext Paris was provided by the IRG (University of Paris 12 - Val de Marne).

^ Corresponding author: Carole Gresse - Université Paris X Nanterre - UFR SEGMI - 200, avenue de la République - 92001 Nanterre cedex FRANCE. E-mail at carole.gresse@u-paris10.fr.
} 


\title{
Centralised Order Books versus Hybrid Order Books: A Paired Comparison of Trading Costs on NSC (Euronext Paris) and SETS (London Stock Exchange)
}

\begin{abstract}
This article aims at comparing the cost of trading on SETS, the hybrid order-driven segment of the London Stock Exchange for the trading of large capitalisations, and NSC, the centralised electronic order book of Euronext. Based on two stock samples paired according to economic sector, free float capitalisation and trading volumes, our research shows that transaction costs are lower on NSC than SETS. By allowing larger transactions, the presence of dealers on SETS admittedly improves immediacy and contributes to the development of the block market, but at the expense of higher execution costs for all other trades and heavier adverse selection and inventory costs inside the order book.
\end{abstract}




\section{Centralised Order Books versus Hybrid Order Books:}

\section{A Paired Comparison of Trading Costs on NSC (Euronext Paris) and SETS (London Stock Exchange)}

Trading costs on a financial market depend on the characteristics of the traded security, but also on the structure of the market, and the order placement strategies of market participants. The rules of trading affect the probability of various trading strategies (Harris (1997)) and hence affect price formation and implicit transaction costs, and the way the market design impacts the cost of trade execution is a fundamental issue. Firstly, it may substantially alter portfolio performances. Recently, basing their research on the order and transaction database of Elkins/McSherry, ${ }^{1}$ Domowitz et al. (2001) study the range of, and the factors determining, trading costs, and analyse the interactions between costs, liquidity and volatility in 42 countries, between September 1996 and December 1998. They offer evidence of a high degree of variability of trading costs across countries, which might limit the gains from international diversification. Secondly, in a context of competition between stock exchanges and of revision of the European ISD, the comparison of trading costs between exchanges with different trading mechanisms is extremely relevant for regulators.

A large number of articles have already compared the liquidity of the two main market models: quote-driven markets as NASDAQ or SEAQ ${ }^{2}$ or most fixed income markets, where market makers commit themselves to post continuously bid and ask prices for minimal quantities of assets, and order-driven markets, as most equity markets, where buy and sell orders originating from final clients are directly matched against one another.

In reality, most stock exchanges have now converged, at least for the trading of Blue Chips, to a common market model: the electronic order book. Even the London Stock Exchange (LSE), where the dealership structure had always been the traditionally prevailing model, finally changed its trading mechanism for Blue Chips. In October 1997, the previous quote-driven system has progressively been replaced by an electronic order-driven system. However, in spite of their common features, some differences in market organisation still remain between auction markets: different tick sizes, different roles and duties assigned to intermediaries etc.

\footnotetext{
${ }^{1}$ Some consultants sell measurements of their trading costs to institutional investors, be they asset managers or brokers. For example, the Elkins/McSherry consultancy, now a branch of the State Street bank, measures explicit and implicit trading costs for institutional investors. Implicit costs are measured by the spread between the investor's trading prices and a reference price calculated as an average of four indicators: the day high, low, opening and closing quotes.
} 
In particular, the rules regulating the off-order-book transactions and internalising practices may differ substantially, so that, on some exchanges, the order flow mainly concentrate in the order book while, on others, the proportion of order flow executed outside the order book is significant. Our study focuses on this last issue and addresses the question of whether trading in a pure order-driven system is less costly than trading in a hybrid order-driven system where dealers still execute a substantial part of the order flow.

To this goal, on the basis of intra-day market data (both orders and trades), we analyse transaction costs on SETS, ${ }^{3}$ the electronic order book open for the trading of Blue Chips at the LSE, and NSC, the electronic order-driven system of Euronext Paris. At the LSE, SETS securities are traded in the order book as well as with dealers off the order book, whereas on Euronext Paris, all stocks are traded on NSC, ${ }^{4}$ which is an almost pure centralised electronic order book, for which a concentration rule ${ }^{5}$ applies.

Our methodology consists in constructing two samples of securities, paired according to their economic sectors, free float market capitalisations and trading volumes. This methodology compares to that of Huang and Stoll (1996a) and Venkataraman (2001). It ensures that empirical results can be assigned to differences in market structures and not to corporate differences in compared stocks. In a first stage, we compute various measures of spreads and their components across the paired samples; in a second stage, we check the quality of the matching procedure and attempt to identify explanatory variables for the observed differences.

Section 1 provides an overview of previous research and sets the testable hypotheses. Section 2 compares the organisation of NSC for Euronext Paris and SETS for the LSE. Section 3 describes the data and the methodology. Section 4 compares both markets' transaction costs and their components. Section 5 investigates to which extent some economic factors may explain the differences and Section 6 concludes.

\footnotetext{
${ }^{2}$ SEAQ is the Stock Exchange Automated Quotations system. This screen-based trading system was introduced on October 27, 1986, as part of the City's Big Bang, to carry market makers' bid and offer quotes and trade reports for UK securities.

${ }^{3}$ The Stock Exchange Electronic Trading Service (SETS) replaced the quote-driven market system for Blue Chips in October 1997.

${ }^{4}$ NSC stands for Nouveau Système de Cotation.

5 The concentration rule implies that any trade has to be executed inside the order book. If a trade is negotiated off the electronic order book, according to Euronext regulation, it should still be executed in the order book (the buyer (the seller) submitting a buy and a sell order simultaneously) at a price inside the bid-ask spread, otherwise all standing limit orders at a better price are to be absorbed before executing the trade.
} 


\section{Previous research and testable hypotheses}

\subsection{Previous literature}

A host of theoretical and empirical papers have compared diverse market structures with different trading rules, different transparency duties, different pricing constraints etc. (Tinic and West (1974), Hamilton (1976), Ho and Macris (1985), Hasbrouck and Schwartz (1986), Marsh and Rock (1986), Reinganum (1990), Madhavan (1992), Biais (1993), Pagano and Roëll (1992, 1996), Affleck-Graves et al. (1994), Biais, Foucault and Salanié (1998)), Keim and Madhavan $(1994,1998))$. Most of these works are in favour of electronic order-driven markets. According to Domowitz et al. (2001), Euronext Paris ranks among the cheapest (30 bp), whereas implicit costs on the LSE before the introduction of the SETS order book locate this exchange among the most expensive. Jain (2001), analyses, in a high number of exchanges, the impact of institutional factors on market performance, measured by quoted, effective and realised spreads, volatility and turnover ratios. The factors identified are: market organisation, trading mechanism, trading system, market transparency, degree of fragmentation, share ownership structure and their variability over time. Based upon the 15 biggest Blue Chips of 51 stock exchanges, Jain (2001)'s study evidences that order-driven market structures record lower costs and volatility than quote-driven markets, and that in Europe, Euronext Paris and the Swiss Stock Exchange show the lowest spreads.

The main limit of these works lays in that they may measure corporate differences between sample stocks instead of market design effects. To eliminate this potential bias, some studies have compared the cost of trading stocks listed on an order-driven exchange and the cost of trading of the same stocks in a competing quote-driven market (Blume and Goldstein (1992), Roëll (1992), De Jong, Nijman and Roëll (1993), Lee(1993), Petersen and Fialkowski (1994), Huang and Stoll (1996b)) generally measure larger spreads on dealer markets. Studying LSE trading in French stocks, Gresse (2001) concludes to a greater depth of the dealer market associated to larger spreads. However, these results may be subject to a domestic bias.

Recent research papers have then made two-market liquidity comparisons by matching samples in order to estimate the impact of the market structure and organisation. Huang and Stoll (1996a) calculate liquidity indicators for the NASDAQ and the NYSE. Their sample is made of pairs of securities from both markets, formed by considering the company sector, long-term debt, share price criteria, as well as the number of admitted shares and the book value. Venkataraman (2001) uses the same methodology to compare the Paris Stock 
Exchange and the NYSE, and matches firms on industry, market price and market size. Our methodology follows this approach.

Finally, while nowadays on almost every stock exchange, large capitalisations are traded in electronic order-driven systems, very few studies focus on the impact of the design of order books on trading costs. Venkataraman (2001) provides a paired comparison of an automated order-driven market and a floor-based order-driven market; closer to our analysis, KaschHaroutounian and Theissen (2003), with matched samples, show that spreads are slightly lower on Xetra (the electronic order book of Deutsche Börse) than on NSC (Euronext Paris), but find that the observed differences are mainly related to corporate factors; yet, to our knowledge, no empirical work put into balance a hybrid order-driven system with multiple dealers and a centralised order-driven system.

\subsection{Testable hypotheses}

Given the relative advantages of dealer and auction systems, many exchanges have chosen mixed structures allowing dealers to negotiate trades outside the order book. Very few studies have compared the liquidity of these mixed systems with the one of pure centralised order books.

On the one hand, dealers may provide additional depth and immediacy to the order book and thus complement the trading services offered by the exchange. Some empirical studies as those of Tinic and West (1974), Jain (2001), Gresse (2001), Swan and Westerholm (2004), conclude to the superiority of such mixed structures. On the other hand, the fragmentation of the order flow may lower the probability of execution in the order book and increase adverse selection costs in the market, and thus be detrimental to liquidity (see Mendelson (1987), Chowdry and Nanda (1991)). Moreover, dealer may skim off profitable uninformed orders from the order book, which would increase spreads in the book (Easley, Kiefer and O'Hara (1996)). Therefore, by using SETS and NSC best quote and trade data, we propose to test the following hypotheses.

\section{Volatility}

H1. As shown in Biais (1993), prices are less volatile on fragmented markets than on centralised markets, so that volatility is lower on a hybrid order-driven market involving multiple dealers in competition beside the book (HOM) like SETS, than on a pure centralised order-driven market (COM) like NSC. 


\section{Spreads and trade size}

H2. The internalisation of a substantial part of the order flow by dealers in a HOM fragments the market and enlarges quoted and effective spreads in comparison with a COM.

H3. Dealers provide additional immediacy in a HOM in comparison with a COM, so that

- trade sizes are superior in the HOM (H3a);

- the marginal cost trading one unit of asset is less in the HOM (H3b);

- large transactions are more expensive in the COM (H3c).

\section{Spread components}

H4. The inventory cost component of spreads is greater in the HOM than in the COM, because of the dealers' liquidity-providing activity beside the order book.

H5. A COM being more transparent by nature, the adverse selection component of its spreads exceeds the one of HOM spreads.

H6. In a HOM, dealers try to attract the least informed part of the order flow, so that the adverse selection risk borne inside the order book of a HOM is more than the one incurred in a COM.

\section{A comparison of the organisations of SETS and NSC}

\subsection{Common features}

The London and Paris markets have similar fundamental characteristics: intermediaries have multiple capacities, which means that they may act either on their own account, possibly in the context of market making, or on account of their clients.

The 1986 reform of the LSE enabled to remove the distinction between brokers and market makers (all financial institutions could from then on, play the role of a market maker), and liberalised pricing regulations. At present, the LSE admits only a single type of intermediaries, the so-called broker-dealers, which have a dual capacity. This reform enabled to introduce SEAQ, a single display system for the quotes of all London listed shares. The second important reform happened in 1997 and led to the creation of SETS, an electronic and continuous order-driven trading system for Blue Chips.

Euronext Paris, for its part, implemented two significant market reforms in 1986 and 1988: 
- the "agents de change" were replaced by the "sociétés de bourse", entitled, like British intermediaries, to act both as brokers or on their own account;

- the old centralised electronic order-driven CAC system was replaced by a new one (now called $\mathrm{NSC}^{6}$ ) with improved functionalities.

On order-driven market systems like NSC or SETS, buy and sell orders coming from final clients are centralised in the order book, where they are automatically matched. Unlike on quote-driven markets, investors themselves provide liquidity by placing limit orders. Securities may be traded either through a call auction, or continuously. On both SETS and NSC, the trading day opens with a call auction, then switches to a continuous auction, and ends with a closing fixing procedure.

\subsection{Main organisational differences between SETS and NSC}

Though both markets have identical central functionalities, some differences remain.

\section{Retail market}

At Euronext Paris, orders from retail clients are routed towards the order book and participate to the general matching of buy and sell orders.

In London, orders from retail clients are mostly processed outside the SETS system: Retail Service Providers (RSP) act as a counterpart to the orders from private brokers. Those orders are in general market orders and are processed at a price at least as favourable as the SETS order book best limit.

\section{Large trades}

On both markets, it is possible to trade blocks without using the automatic order matching system. Moreover, Euronext adds a frequently used functionality, called cross trades. A cross trade (applications) is an already matched trade entered by an exchange member who found a buyer and a seller (he can act on his own account as a counterpart of a client, but can also execute client orders against one another). Cross trades have to be processed at a price in the range between the order book buy and sell best limits at the time of the trade. Once entered into the trading system cross trades become immediately visible by all market members.

\footnotetext{
${ }^{6}$ This system was later adopted by all of Euronext equity markets.
} 


\section{Ordinary trades}

At the LSE, any trade can be freely executed either electronically in the order book, or off the order book with a dealer without any constraint on execution prices. The only obligation for the dealer who executes the trade is to report the transaction within $3 \mathrm{mns}$ to the exchange. Conversely, on Euronext, any trade that is not a block trade eligible to the specific block trade procedure has to be executed automatically inside the order book at a price that is compatible with standing limit orders according to the so-called concentration rule.

Table 1 synthesises the differences between SETS and NSC.

\section{Table 1 about here}

\section{Data and methodology}

\subsection{Stock selection and sample matching}

The present research considers all spreads and trades during the first semester of 2001 . Trading data and quotes were extracted from the $\mathrm{BDM}^{7}$ market database as far as Euronext Paris is concerned, and from the intra-day database of the LSE (Transaction Data Service). Our sample contain all securities that belong to the index $S B F 250$ for the French market or to the index FTSE250 for the British market at the date of January the $1^{\text {st }}$ of 2001, excluding those for which quotes are available for less than 10 days in any month of the observation period and Euronext stocks that are traded at daily call auctions only. These criteria produce a sample of 211 securities for the French market and 492 for the British market from which 157 are listed on SETS.

To pair the samples from Euronext Paris and the LSE, a pairing algorithm almost similar to that of Huang and Stoll (1996a) and Venkataraman (2001) was used, which relates securities according to:

- their Dow Jones Economic Sector, ${ }^{8}$

- their free float on January 2001, according to Dow Jones Indexes free float definition, ${ }^{9}$

- their total trading volumes in euros during the first semester of 2001.

\footnotetext{
7 "Bases de données de marché".

${ }^{8}$ Dow Jones indexes classification considers ten economic sectors: Basic Materials, Consumer Cyclical, Consumer Non-cyclical, Energy, Financial, Healthcare, Industrial, Technology, Telecommunications, Utilities.

${ }^{9}$ The free float of a security is equal to its market capitalisation minus cross-participations of $5 \%$ or more held by public organisations or individuals.
} 
The Dow Jones sector was available for only 96 Euronext firms; for each of these 96 Euronext-listed companies, all possible pairs with LSE-listed firms of the same sector were considered. Among all LSE stocks belonging to the same sector as the Euronext stock i, the London security $\mathrm{j}^{*}$ that minimised the difference between the two pairing characteristics other than the industrial sector, was retained:

$$
\operatorname{Min}_{j} \sum_{p=1}^{2}\left[\frac{X_{i p}^{\text {Euronext }}-X_{j p}^{L S E}}{\left(X_{i p}^{\text {Euronext }}+X_{j p}^{L S E}\right) / 2}\right]^{2}
$$

where

$-X_{i p}^{\text {Euronext }}$ is the value of the $\mathrm{p}^{\text {th }}$ match criterion for stock i on Euronext Paris;

$-X_{j p}^{L S E}$ is the value of the $\mathrm{p}^{\text {th }}$ match criterion for stock $\mathrm{j}$ on the LSE.

The joint match resulted in 55 pairs of firms. The comparison of the matched samples is developed in Section 4.

\subsection{Measurement of implicit trading costs}

A financial market participant bears two types of trading costs: explicit and implicit trading costs, the latter resulting from the difference between bid and ask prices. The study only focuses on implicit costs by looking at diverse measures of spreads.

\subsubsection{Quoted spreads}

On agency markets, where quotes appear in the order book, quoted spreads refer to the best buy and sell limits. They measure the cost that would be borne by an investor that would buy and immediately sell a security whose fundamental value remains unchanged, for a quantity lower or equal to the quantities available at the order book best limits.

$$
\text { Quoted spread }=\frac{(\text { Best selling limit }- \text { Best buying limit })}{\text { Mid }}
$$

For each stock, the time-weighted average quoted spread over the whole observation period is computed, then an equally-weighted mean of individual averages is calculated across each sample. 


\subsubsection{Effective spreads}

Effective spreads measure the implicit cost borne in a transaction by the one out both counterparts that is demanding liquidity. ${ }^{10}$

The effective spread is expressed as a difference between the price of a trade and the midprice of the best bid and ask prices, just before the trade happens.

$$
\text { Effective spread }=2 \times \frac{\mid \text { Trading price }- \text { Mid } \mid}{\text { Mid }}
$$

For each stock, two averages of effective spreads are calculated for the total observation period: an equally-weighted mean and a quantity-weighted mean of effective spreads. Then, markets are compared on the basis of the samples' equally-weighted mean.

\subsubsection{Effective marginal costs}

To compare execution costs on actual trades, we also use an empirical estimation of the Kyle $\lambda$ coefficient, which represents the variation in price necessary to trade a marginal unit of asset immediately (Kyle (1985)). Kyle (1985) models the cost of liquidity as a linear function of the traded quantity: at equilibrium, $\mathrm{P}$, the traded price equals $\mu+\lambda Q$, where $\mu$ is the risky asset's fundamental value, $\mathrm{Q}$ is the signed trade size and $\lambda$ is an illiquidity parameter. Kyle interprets $1 / \lambda$ as the depth measure as it equals the marginal quantity immediately tradable without no price impact. Assuming that the mid price quoted at the time of a trade is the best estimate of the stock's fundamental value, the $\lambda$ coefficient may be estimated from the trade characteristics by $\left|\frac{\text { Trading price-Mid }}{Q}\right|$. Unfortunately, this measure is sensitive to corporate actions and price level, and does not allow unbiased cross-sectional comparisons. Reporting the relative effective spread to the monetary trade size provides a measure of the marginal cost of immediacy that is insensitive to price level:

$$
\text { Effective marg inal cos } t=\frac{\frac{\mid \text { Trading price }- \text { Mid } \mid}{\text { Mid }}}{\text { Trade size in euros }}
$$

\footnotetext{
${ }^{10}$ Cross trades on Euronext can only be made at prices comprised between the order book best buy an sell prices at the time of the trade. Thus, for this category of trades, the effective spread is necessarily lower than the quoted spread. Both in London and in Paris, for trades processed in the order book, on the reverse, a new order is at best, matched only at the best limit on the other market side, and possibly by other less favourable limits if the quantity offered for the best bid price is not sufficient: for these transactions, the effective spread is thus necessarily bigger than the quoted spread.
} 
The "effective marginal cost" as calculated in equation (4) may be viewed as the marginal increase in spread (in \%) supported to buy or sell $1 €$ of capital immediately. For each stock of our samples, this ratio is computed with trade sizes in thousand $€$ and averaged on both an equally-weighted and a quantity-weighted basis. Sample means are equally-weighted.

\subsection{Measurement of spread components}

Spreads are static measures of execution costs. Another way of comparing transaction costs consists in considering the dynamics of quotes and trade prices and temporary price changes, to estimate the weight of the different components of the spreads on each market, which are order-processing, adverse selection and inventory costs. As dealers execute a substantial part of the order flow of the SETS hybrid system, we could fairly expect inventory costs to be superior on SETS than on NSC (hypothesis H4).

The methods of spread decomposition existing in the literature divide into two main categories: a first group of methodologies based on the covariance of transaction price variations (Stoll(1989), George, Kaul and Nimalendram (1991)), a second group of works based on trade direction (Glosten and Harris (1988), Lin, Sanger and Booth (1995), Madhavan, Richardson and Roomans (1997) and Huang and Stoll (1997)). As trade direction can be identified from our intra-day data, we choose the second approach. Moreover, given that we aim at measuring the impact of dealer activity around the order book on the inventory cost component, we need a three-way decomposition methodology, which leads us to select the Huang and Stoll's model.

Huang and Stoll (1997) first propose a two-way spread decomposition in which $\lambda$ is the proportion of the effective spread attributable to adverse selection and inventory costs and $1-\lambda$ corresponds to the part due to order processing costs. They model the effective spread as a constant $S$ expressed in monetary units. $S$ and $\lambda$ are GMM estimated on the basis of the following equation:

$$
\Delta P_{t}=\frac{S}{2}\left(Q_{t}-Q_{t-1}\right)+\lambda \frac{S}{2} Q_{t-1}+e_{t}
$$

where

$-P_{t}$ is the price of the transaction at time $\mathrm{t}$;

$-Q_{t}$ is the buy-sell trade indicator of the transaction at time t;

$-e_{t}$ is an error term. 
In a second stage, Huang and Stoll (1997) decompose the $\lambda$ parameter into an adverse selection component $\alpha$ and an inventory cost component $\beta$ (with $\lambda=\alpha+\beta$ ), using the assumption that, under inventory models, changes in quotes affect the subsequent arrival rate of trades and thus induce a serial correlation in trade flows. From there, they derive two estimation procedures. The first one requires to estimate four parameters, $S, \alpha, \beta$ plus $\pi$, the probability of a reversal in trade sign, from the following system:

$$
\begin{aligned}
& Q_{t-1}=(1-2 \pi) Q_{t-2}+\eta_{t} \\
& \Delta P_{t}=\frac{S}{2} Q_{t}+(\alpha+\beta-1) \frac{S}{2} Q_{t-1}-\alpha \frac{S}{2}(1-2 \pi) Q_{t-2}+e_{t}
\end{aligned}
$$

The second procedure they develop uses the mid-quote variation instead of the transaction price variation, and the observed posted spread that prevails at the time of a trade instead of the constant spread $S$, which reduces to three the number of parameters to estimate. These three parameters, $\alpha, \beta$ and $\pi$ are estimated in order to verify:

$$
\begin{aligned}
& Q_{t-1}=(1-2 \pi) Q_{t-2}+\eta_{t} \\
& \Delta M_{t}=(\alpha+\beta) \frac{S_{t-1}}{2} Q_{t-1}-\alpha(1-2 \pi) \frac{S_{t-2}}{2} Q_{t-2}+e_{t}
\end{aligned}
$$

where $M_{t}$ and $S_{t}$ are respectively the mid-quote and the quoted spread prevailing just before the trade time t. We utilise the second methodology as it produces a higher frequency of convergence of the GMM iteration algorithm. Moreover, as shown in Huang and Stoll (1997), splitting order practices in order books possibly biases the estimation of the $\alpha$ parameter by generating undervalued $\pi$ estimates. To deal with this bias, consecutive trades at the same price, on the same side of the market, within a $2 \mathrm{mn}(3 \mathrm{mn})$ window on NSC (SETS), and with no change in the bid and ask quotes, are bunched into one single trade. ${ }^{11}$

\footnotetext{
${ }^{11}$ This procedure probably overcorrects the problem. Consequently, empirical results provide upper bounds on $\alpha$ and $\pi$.
} 


\section{Comparative analysis of trading costs on SETS and NSC}

\subsection{Volatility, spreads and trading characteristics}

Table 2 reports descriptive statistics on volatility, trading costs, quote and trade frequency, volumes and trade sizes, for the paired samples. The figures show that the structure of the order flow greatly differs from one stock exchange to the other. More than a half of trading volumes in euros and in number of trades are executed by dealers outside the order book at the LSE. Trades are less frequent but larger on SETS than on NSC: the average size of an order-book (off-order-book) trades in a SETS stock reaches 1.4 (2.9) times the one of a NSC trade, while the average number of trades per day on SETS (all trades combined) is twice the one on NSC, which confirms H3a.

\section{Table 2 about here}

The average daily return volatility of SETS stocks significantly exceeds the one of NSC stocks, although the difference is less than $0.5 \%$, so that we reject hypothesis $\mathrm{H} 1$.

Quoted spreads, effective spreads and marginal costs are significantly higher on SETS than on NSC, which validates $\mathrm{H} 2$ but invalidates $\mathrm{H} 3 \mathrm{~b}$. The tighter quoted spreads on NSC are related to a superior frequency of quote revisions. Besides, the difference in effective spreads is less than the one in quoted spreads. In fact, in the SETS environment, investors may often improve the price of a trade compared to the best limits observed in the order book, while on NSC, prices displayed at the best limits most frequently relate to actual trading prices. NSC best limits thus appear as a better indicator of the value at which a share is potentially tradable, which makes NSC more transparent in terms of pre-trade transparency.

A breakdown of average effective spreads by 9 classes of transaction size is presented in Table 3. It shows that SETS average effective spreads on order book trades (iob) are larger than NSC spreads for every class of trades, the single exception being class 9 (trade size $>$ 2,500 thousand $€$ ) for which the difference does not significantly exceeds 0 . SETS off-orderbook trades are more expensive than SETS order book trades whatever the class that is considered, and the spread difference increases with trade size. However, the weight of large trades in the distribution of volumes is greater in London than in Paris: as instance, classes 7 to 9 account for $52 \%$ of total trading volumes and $3.4 \%$ of the total number of trades while these percentages are respectively $33 \%$ and $1.3 \%$ on NSC. Moreover, with regard to classes 8 and 9, the main part of SETS stock trades are executed out of the order book: as a matter of 
fact, it is much easier to negotiate such trades with dealers on the phone, like in an upstairs market, than to find the required depth in the order book. Two other classes have more trades executed out of the book at the LSE: class 2 and above all class 1, which conforms to the fact that retail orders are not routed to the order book but to specialised dealers, the so-called RSPs. Given the class 1 and class 2 spread statistics, these retail orders could find more favourable execution inside the order book. In conclusion, with regard to immediacy, our results allow us to validate $\mathrm{H} 3 \mathrm{a}$ and to reject $\mathrm{H} 3 \mathrm{~b}$ whereas $\mathrm{H} 3 \mathrm{c}$ only holds for very large trades.

\section{Table 3 about here}

All things combined, effective spreads are higher on SETS, where transactions are also larger and less frequent. The SETS market is globally more expensive but offers superior immediacy in counterpart. This is particularly actual for class 9, which can be viewed as a block trade segment. First, as we already mentioned, it is the only class for which SETS order book trading costs are equivalent to those observed on NSC. Second, although the average effective spread on SETS off-order-book class-9 trades is apparently superior to the one measured on NSC class-9 trades, it applies to bigger and more numerous trades of whom many would not even be tradable on Euronext Paris. ${ }^{12}$

\subsection{Spread components}

Using GMM, we estimate the $\lambda$ and the $S$ parameters of equation (5) in a first stage, and the $\alpha, \beta$ and $\pi$ parameters of system (7) in a second stage, for both samples of stocks. Concerning SETS stocks, two cases are considering: the total universe of trades combining order book and off-order-book ${ }^{13}$ trades and the universe of book trades only (excluding trades executed by dealers).

\subsubsection{The two-way decomposition: the order processing components versus other components}

Table 4 displays descriptive statistics of the $\lambda$ estimates.

Table 4 about here

\footnotetext{
${ }^{12}$ In fact, this category of transactions are tradable through a special block trade procedure available on Euronext Paris for the largest capitalisations. Block trade data are not part of the public data we use here, but Gajewski and Gresse (2004) have analysed them over April 2002 and found that they represented little volume and were much more costly than LSE block trades.

${ }^{13}$ VWAP trades are always excluded of the analysis.
} 
The estimated values indicate that the order processing component of spreads is maximum for SETS stocks when all trades are taken into account, but is minimum for SETS order book trades, the mean $1-\lambda$ estimated value for Euronext stocks being intermediary. However, the difference in $\lambda$ between the SETS order book (off-order-book trades excluded) and Euronext is not as significant as the difference observed between SETS (all trades included) and Euronext.

In other words, the component of spreads due to adverse selection and inventory costs is lower on the hybrid market than on the centralised auction market, but this is attributable to the trades executed by dealers outside the order book. When considering all trades on SETS (i.e. including those made outside the order book), the presence of dealers may logically increase the order processing cost component. Conversely, in a centralised auction market like Euronext, limit order traders do not bear all the direct costs incurred by dealers.

Moreover, the two segments of SETS probably do not attract the same type of investors. The informed will have a tendency to capture limit orders in the order book while the dealers will try to attract the less informed order flow (retail investors, institutional investors).

\subsubsection{The three-way decomposition: adverse selection versus inventory holding}

In order to distinguish the adverse selection cost component from the inventory cost component, we now use the Huang and Stoll' three-way decomposition methodology corresponding to system (7). The GMM estimation procedure converged to consistent estimates $(0<\alpha<1$ and $0<\beta<1)$ for only 18 stocks listed on SETS and 25 listed on Euronext. The model most performed for SETS securities when off-order book are excluded from the data. In that case, the GMM algorithm converged to correct estimates for 44 stocks. Table 5 displays descriptive statistics on the estimated values.

\section{Table 5 about here}

The $\pi$ probabilities, corresponding to the probability of a reversal in trade direction, are inferior to 0.5 for all SETS stocks and for 11 NSC stocks upon 25, which, unexpectedly, means that order persistence is higher on SETS. This is probably related to the smaller frequency of trades in the SETS market. Conversely to the intuition, $\beta$ coefficients, that is the percentage of spread assignable to inventory costs, are greater for order books (NSC and SETS with in-order-book trades only) than for the hybrid case (SETS all trades combined), so that $\mathrm{H} 4$ is rejected. Furthermore, the mean $\beta$ coefficient obtained on SETS order book trades 
$(25.57 \%)$ is significantly superior to the one measured on NSC (17.43\%). This counterintuitive result could be due to dealers' market practices as those identified in Jacquillat and Gresse (1998): when market makers are competing with an order book, they tend to trade preferably in the order book when they need to rebalance inventories. We suspect SETS stocks to be subject to such strategies, so that inventory costs are not directly reflected by the off-order-book order flow but affect the order book.

As for $\alpha$ coefficients, the highest cross-sectional mean value is observed once again for SETS in-order-book trades $(28.60 \%)$. This value decreases dramatically when off-order-book trades are included (5.82\%) in the analysis. NSC $\alpha$ coefficients are slightly but significantly superior at the $10 \%$ threshold, with a cross-sectional mean equal to $9.24 \%$. These findings confirm what we suspected with regard to the two-component decomposition: most probably, the informed and the uninformed cluster between the order book and the off-order-book market, with the major part of the uninformed orders being executed by dealers. In so, we fail to reject hypotheses $\mathrm{H} 5$ and $\mathrm{H} 6$.

As these observations could be due to sample distortions, we focus on the pairs of securities for which the model was correctly estimated for both stocks of the pair. 7 pairs are identified and the estimated $\pi, \alpha$ and $\beta$ coefficients for each member of these pairs are reported in Table 6. They confirm our conclusions.

Table 6 about here

\section{Which economic factors or institutional specifics best explain the difference in execution costs?}

Given the significant difference in trading costs of matched Euronext and SETS stocks, a natural question is whether the stocks are actually well matched. Another possibility is that some economic variables not included in the matching procedure explain the observed differences. These variables comprise stock characteristics such as return volatility or price, trading characteristics like the number of trades per day or the imbalance between purchases and sales, or finally institutional features including tick size or fragmentation degree.

\subsection{Stock characteristics}

Theoretical models of the bid-ask spread suggest that execution costs differ systematically by firm-specific characteristics such as volatility, market size, and stock price. Market size is part of our matching criteria. We measured it as the floating market value of the firm at the 
beginning of the observation period. The rationale for the use of this variable is that firm size, and more specifically floating capitalisation, asserts the probability of locating a counterparty for a trader (Stoll(2000)), and empirically, spreads are negatively related to market value (Huang and Stoll (1996a), Stoll(2000), Venkataraman (2001)...). Another fundamental variable which positively affects spreads, is daily return variance, ${ }^{14}$ as it measures the risk of adverse price changes of a stock put into inventory. For each stock, we calculate the monthly variance of daily returns calculated in logarithm on closing mid-quotes. The third corporate specific we consider is price level measured as the monthly average closing mid-quote in $€$. The cross-sectional relation between spreads and price is usually negative, reflecting the fixed order-processing component of spreads (Venkataraman (2001)), and also because price is an additional proxy for risk in that low price stocks tend to be riskier and because of the fixed order-processing component of spreads (Stoll (2000)). On that point, there is a structural difference in stock price between LSE and Euronext securities, price levels being, in practice, substantially inferior on the LSE.

\subsection{Trading characteristics}

On top of the variables previously mentioned, the cross-section of spreads is generally related to two firms' trading characteristics: trading volume and number of trades, the main one being trading volume which serves as matching factor. Trading costs vary inversely to trading volume and trade frequency, as they reflect economies of scale and lower inventory and adverse selection costs. For the same reasons, Stoll (2000) shows that spreads are positively to order imbalance. For each stock and each month of the observation period, we then calculate the following variables: the daily average trading volume in thousand $€$, the average number of trades per day, the average imbalance per day measured by $\mid$ buy volumes - sell volumes $\mid /($ buy volumes + sell volumes $)$.

\subsection{Institutional features}

We consider two main institutional differences that could explain execution costs: tick size and trading volumes outside the order book. For a given stock and a given month, we calculate the tick variable in percentage by dividing the tick size in $€$ by the average closing mid price in $€$. The percentage of volume traded out of the order book is set to zero for all Euronext stocks and equals the ratio off-order-book volume over total intra-day volume for

\footnotetext{
${ }^{14}$ Stoll (1978) shows theoretically that total risk, not systematic risk, is the relevant measure because the unwanted inventory
} 
each SETS stock on a given day. Monthly stock-by-stock means of this variable are then calculated.

\subsection{Regression design and results}

We run cross-sectional regressions using stock-by-stock monthly average values of spreads and their explaining variables. The general tested model stands as follows:

$$
\begin{aligned}
\Delta s_{t}^{i, j}=a_{0}+b_{1} \Delta & \sigma_{t}^{i, j}+b_{2} \Delta \ln V_{t}^{i, j}+b_{3} \Delta \ln F M V_{t}^{i, j}+b_{4} \Delta \ln P_{t}^{i, j} \\
& +b_{5} \Delta \ln N_{t}^{i, j}+b_{6} \Delta I_{t}^{i, j}+b_{7} \Delta t i c k_{t}^{i, j}+b_{8} F R_{t}^{j}+\varepsilon_{i t}
\end{aligned}
$$

where

$-\Delta s_{t}^{i, j}$ is the difference in average spread between the Euronext stock $\mathrm{i}$ and its matched SETS stock $\mathrm{j}$ over the month $\mathrm{t}$; three measures of average spreads are considered, the time-weighted average quoted spread ( $\Delta s \equiv \Delta a q s)$, the equallyweighted average effective spread ( $\Delta s \equiv \Delta a e s)$ and the quantity-weighted average effective spread ( $\Delta s \equiv \Delta w e s)$;

$-\Delta \sigma_{t}^{i, j}$ equals stock i’s daily return volatility minus stock j’s daily return volatility over month t;

- $\Delta \ln V_{t}^{i, j}=\ln \left(V_{t}^{i}\right)-\ln \left(V_{t}^{j}\right)$, with $V_{t}^{i}$ being the average daily trading volume of stock $\mathrm{i}$ in thousand $€$ over month $\mathrm{t}$;

- $\Delta \ln F M V_{t}^{i, j}=\ln \left(F M V^{i}\right)-\ln \left(F M V^{j}\right)$, with $F M V^{i}$ being the floating market value in thousand $€$ of stock $i$ at the start of January 2001;

- $\Delta \ln P_{t}^{i, j}=\ln \left(P_{t}^{i}\right)-\ln \left(P_{t}^{j}\right)$, with $P_{t}^{i}$ denoting the average closing mid-quote of stock i for month t;

$-\Delta \ln N_{t}^{i, j}=\ln \left(N_{t}^{i}\right)-\ln \left(N_{t}^{j}\right)$ is the difference in the average number of trades per day taken in logarithm, of stock $\mathrm{i}$ with its paired stock $\mathrm{j}$, over month $\mathrm{t}$;

$-\Delta I_{t}^{i, j}$ is the difference in the average imbalance per day $\mathrm{t}$ of stock $\mathrm{i}$ with its paired stock j, over month t;

- $\Delta t i c k_{t}^{i, j}=t i c k_{t}^{i}-t i c k_{t}^{j}$ and $t i c k_{t}^{k}$ is the tick in percentage of the average closing mid-price for stock $\mathrm{k}$ and month $\mathrm{t}$; 
$-F R_{t}^{j}$ is the order flow fragmentation rate during month $\mathrm{t}$ for the SETS stock $\mathrm{j}$ matched to the Euronext stock i measured by off-order-book volume over total intra-day trading volume;

$-\varepsilon_{i t}$ is the error term.

Computing variance inflation factors for the variables included in regression (8) detects a collinearity relation between three variables: the constant variable, the difference in price $\Delta P$, and the fragmentation rate $F R$. For that reason, the model displayed in equation (8) is not estimated directly but three alternative regressions are run separately. In the first one, the $\Delta P$ and $F R$ variables are dropped:

$$
\begin{aligned}
\Delta s_{t}^{i, j}=\alpha_{0}+\alpha_{1} \Delta \sigma_{t}^{i, j}+\alpha_{2} \Delta \ln V_{t}^{i, j}+\alpha_{3} \Delta \ln F M V_{t}^{i, j}+ & \alpha_{4} \Delta \ln N_{t}^{i, j} \\
& +\alpha_{5} \Delta I_{t}^{i, j}+\alpha_{6} \Delta t i c k_{t}^{i, j}+\varepsilon_{i t}
\end{aligned}
$$

The second one has no intercept but includes $\Delta P$ :

$$
\begin{aligned}
\Delta s_{t}^{i, j}=\beta_{1} \Delta \sigma_{t}^{i, j}+\beta_{2} \Delta \ln V_{t}^{i, j}+\beta_{3} \Delta \ln F M V_{t}^{i, j}+\beta_{4} \Delta \ln N_{t}^{i, j}+\beta_{5} \Delta I_{t}^{i, j} & \\
& +\beta_{6} \Delta t i c k_{t}^{i, j}+\beta_{7} \Delta \ln P_{t}^{i, j}+\varepsilon_{i t}
\end{aligned}
$$

Finally, the third linear model has no constant either but the fragmentation rate variable is introduced instead of the price variable:

$$
\begin{aligned}
\Delta s_{t}^{i, j}=\gamma_{1} \Delta \sigma_{t}^{i, j}+\gamma_{2} \Delta \ln V_{t}^{i, j}+\gamma_{3} \Delta \ln F M V_{t}^{i, j}+\gamma_{4} \Delta \ln N_{t}^{i, j} & +\gamma_{5} \Delta I_{t}^{i, j} \\
& +\gamma_{6} \Delta t i c k_{t}^{i, j}+\gamma_{7} F R_{t}^{j}+\varepsilon_{i t}
\end{aligned}
$$

The comparison of the three different models will permit of identifying which factor among the market place, the price level, or the fragmentation rate best explain the cross-sectional variance of spreads. Regressions are OLS-estimated but $\mathrm{t}$ statistics and $\mathrm{R}^{2}$ values are corrected for heteroskedasticity following White (1980). Results are displayed in Table 5.

\section{Table 5 about here}

The difference in floating market value does not significantly impact any of the differences in spread (except in one regression at the $10 \%$ threshold), proving that samples are well matched on this criterion. The $\Delta \ln V$ coefficients are nearly always significantly negative, which indicates that the matching is not perfect for this variable and that the differences in volumes partially explain the differential spreads. Unsurprisingly, volatility appears to be the major explaining factor: coefficients for this independent variable are all positive, as expected, and 
associated with the highest t-values. Differences in spread are positively related to imbalance differences (except in the case of $\Delta$ wes), while the number of trades, with significantly negative coefficients in only 3 regressions, has a weak explanatory power. Finally, the difference in price has a substantial impact and affect spreads in the expected way.

Let us focus now on institutional features. Consistently with Ronen and Weaver (2001), all measures of differential spreads, $\Delta a q s, \Delta a e s$ and $\Delta w e s$, significantly increase with the difference in tick size. This positive link between ticks and spreads cannot be assigned to the fact that $\Delta t i c k$ could play the role of a proxy for price level, as, when $\Delta P$ is introduced in the model (regression design (10)), the tick coefficients remain significant at the $1 \%$ level. Regressions designed as equation (9) have a significant positive intercept for the three measures of differential spread, meaning that even when controlling for stock characteristics and tick size, spreads are still superior at the LSE than on Euronext. Their adjusted $\mathrm{R}^{2}$ exceeds the ones we obtain in the regressions of type (10), which evidences that the fact that a security is traded on SETS rather than on NSC (represented by the constant variable) has more explanatory power for the difference in executions costs than the difference in price. When the constant is replaced by the SETS stock's fragmentation rate, adjusted $\mathrm{R}^{2}$ increase for every measure of spreads. The fragmentation rate coefficients are all positive and their $\mathrm{t}$ values are superior to those associated to the intercepts in regressions of type (9). This finding leads us to the conclusion that the main feature explaining the excess in spread on SETS is the market activity of dealers outside the order book, confirming hypothesis H2.

\section{Conclusion}

Both SETS and NSC are electronic order-driven systems with similar functionalities. The main difference lies in that a great part of the order flow in SETS stocks is executed by dealers out of the order book while almost all trades in Euronext stocks are executed inside the NSC order book. More than a half of trading volumes in euros and in number of trades are actually executed by dealers outside the SETS order book. In order to measure the impact of this fragmentation of the order flow on execution costs, we compare two samples of stocks matched on economic sector, free float capitalisation and trading volumes, and find substantial differences in the trading characteristics of both markets. First, although the risk level of both samples' stocks are of similar range, the variance of closing returns is significantly higher for SETS stocks. Second, all measures of trading costs (quoted spreads, effective spreads and marginal costs) are in favour of NSC. Concerning effective spreads, a 
breakdown per class of trade size shows that SETS in-order-book average effective spreads are larger than NSC spreads for every class except for trades over 2,500 thousand $€$. The distribution of trade sizes evidences that transactions are larger and less frequent in the hybrid order-driven market. This market is globally more expensive but offers superior immediacy in counterpart.

To interpret the spread differences, we proceeded to spread decompositions in a first stage, and to cross-sectional regressions involving economic and institutional determinants of spreads in a second stage. The spread decompositions state that the order processing cost component logically accounts for a much bigger part of the spread on the hybrid market than on the centralised order book. Moreover, the weight of the inventory holding component is, conversely to the intuition, higher on NSC than on SETS, but is maximum on SETS when considering order book trades only. This might be the reflection that, at the LSE, dealers probably trade in the SETS order book when they need to rebalance inventories. The adverse selection component rises to relatively comparable levels on SETS and NSC; yet, when excluding off-order-book trades from the SETS dataset, it increases dramatically. We interpret this result as a possible clustering of trades between SETS market segments according to their informational content, the dealers skimming off the least informed. The cross-sectional analyses put forward that two institutional features explain the differential spreads between SETS and NSC: the tick size and the share of volume executed by dealers in the SETS market, the latter having the highest significance.

We conclude that the dealers' market activity beside the order book brings additional immediacy and contributes to the development of an efficient block market, but, in counterpart, is unfavourable to small and medium traders who pay higher execution costs than on a centralised order book. 


\section{References}

Affleck-Graves, John, Shantaram P. Hegde and Robert E. Miller, 1994, "Trading mechanisms and the components of the bid-ask spread," The Journal of Finance, v(49)4, 1471-1488.

Biais, Bruno, 1993, "Price Formation and Equilibrium Liquidity in Fragmented and Centralised Markets," The Journal of Finance, v48, 157-185.

Biais, Bruno, Thierry Foucault and François Salanié, 1998, "Floors, dealer markets and limit order markets," Journal of Financial Markets, v1(3-4), 253-284.

Blume, Marshall E. and Michael A. Goldstein, "Displayed and Effective Spreads by Market," Working paper, Rodney White Center, The Wharton School, University of Pennsylvania.

Chowdry, B. and V. Nanda, 1991, "Multimarket trading and market liquidity," The Review of Financial Studies, v(4)3, 483-511.

De Jong Franck, Theo Nijman and Ailsa Roëll, 1995, “A Comparison of the Cost of Trading French Shares on the Paris Bourse and on SEAQ International," European Economic Review, v39(7), 1277-1301.

Domowitz, Ian, Jack Glen and Ananth Madhavan, 2001, "Liquidity, Volatility and Equity Trading Costs Across Countries and Over Time," International Finance, v4(2), 221255.

Easley, D., N. M. Kiefer, and M. O’Hara, 1996, “Cream-Skimming or Profit-Sharing? The Curious Role of Purchased Order Flow," The Journal of Finance, v51(3), 811-833.

Gajewski, Jean-François and Carole Gresse, 2004, "A Comparison of Trading Costs on NSC (Euronext) and SETS (London Stock Exchange)," Revue Bancaire et Financière, Forthcoming.

George, Thomas J., Gautam Kaul and M. Nimalendram, 1991, "Estimation of the Bid-Ask Spread and Its Components: A New Approach," The Review of Financial Studies, v4(4), 623-656.

Glosten, Lawrence R. and Lawrence E. Harris, 1988, "Estimating the Components of the BidAsk Spread," Journal of Financial Economics, v21, 123-142. 
Gresse, Carole, 2001, Fragmentation des Marchés d'Actions et Concurrence entre Systèmes d'Echange, Economica, Paris.

Hamilton, John L., 1976, "Competition, scale economies and transaction cost in the stock market," Journal of Financial and Quantitative Analysis., v(11)5, 779-802.

Harris, Lawrence E., 1997, “Order Exposure and Parasitic Traders," Working paper, University of Southern California.

Hasbrouck, Joël and Robert A. Schwartz, 1986, "The liquidity of alternative market centres : A comparison of the New York Stock Exchange, the American Stock Exchange and the NASDAQ National Market System," American Stock Exchange Transactions Data Research Project, Report \#1.

Ho, Thomas S. and Richard G. Macris, 1985, "Dealer market structure and performance," in Yakov Amihud, Thomas Ho et Robert Schwartz eds, Market making and the changing structure of the securities industry, Lexington Books.

Huang, Roger D. and Hans R. Stoll, 1996a, "Dealer versus Auction Markets: A Paired Comparison of Execution Costs on NASDAQ and the NYSE," Journal of Financial Economics, v41(3), 313-357.

Huang, Roger D. and Hans R. Stoll, 1996b, "Competitive Trading of NYSE Listed Stocks: Measurement and Interpretation of Trading Costs," Financial Markets, Institutions and Instruments, v5(2), 1-55.

Huang, Roger D. and Hans R. Stoll, 1997, "The Components of the Bid-Ask spread: A General Approach,” The Review of Financial Studies, v10(4), 995-1034.

Jacquillat, Bertrand and Carole Gresse, 1998, “The Diversion of Order Flow on French Stocks from CAC to SEAQ International: a Field Study," European Financial Management, $\mathrm{v} 4(2), 121-142$.

Jain, Pankay, 2001, “Institutional Design and Liquidity on Stock Exchanges," Working paper, Kelley School of Business - Indiana University.

Kasch-Haroutounian, Maria and Erik Theissen, 2003, "Competition between Exchanges: Euronext versus Xetra," Working paper, University of Bonn. 
Keim, Donald B. and Ananth N. Madhavan, 1994, “Anatomy of the trading process: empirical evidence on the behavior of institutional traders," Journal of Financial Economics, v37(3), 371-398,

Keim, Donald B. and Ananth N. Madhavan, 1998, "The Cost of Institutional Equity Trades," Financial Analysts Journal, v54(4), 50-69.

Kyle, Albert S., 1985, "Continuous Auction and Insider Trading," Econometrica, v53(6), $1315-1336$.

Lee, Charles M. C., 1993, "Market Integration and Price Execution for NYSE-listed Securities," The Journal of Finance, v48(3), 1009-1038.

Lin, Ji-Chai, Gary C. Sanger and G. Geoffrey Booth, 1995, "Trade Size and Components of the Bid-Ask Spread,” The Review of Financial Studies, v8(4), 1153-1183.

Madhavan, Ananth N., 1992, "Trading mechanisms in security markets," The Journal of Finance, v47(2), 607-642.

Madhavan, Ananth N., Matthew Richardson and Mark Roomans, 1997, "Why Do Security Prices Change? A Transaction-Level Analysis of NYSE Stocks," The Review of Financial Studies, v10(4), 1035-1064.

Marsh, Terry A. and Kevin Rock, 1986, "Exchange listing and liquidity : A comparison of the American Stock Exchange with the NASDAQ National Market System," American Stock Exchange Transactions Data Research Project, Report \#2.

Mendelson Haim, 1987, "Consolidation, fragmentation, and market performance," Journal of Financial and Quantitative Analysis, v(22)2, 189-207.

Pagano, Marco and Ailsa Roëll, 1992, "Auction and Dealership Markets: What is the Difference?," European Economic Review, v36(2/3), 613-623.

Pagano, Marco and Ailsa Roëll, 1996, “Transparency and Liquidity: A Comparison of Auction and Dealer Markets with Informed Trading," The Journal of Finance, v51(2), $579-611$.

Petersen, Mitchell A. and David Fialkowski, 1994, "Posted versus Effective Spreads: Good Prices or Bad Quotes?,” Journal of Financial Economics, v35(3), 269-292. 
Reinganum, Marc R., 1990 "Market microstructure and asset pricing: An empirical investigation of NYSE and NASDAQ securities," Journal of Financial Economics, $\mathrm{v}(28) 1,127-148$.

Roëll, Ailsa, 1992, "Comparing the Performance of Stock Exchange Trading Systems," in J. Fingleton and D. Schoemaker, eds, The Internationalization of Capital Markets and the Regulatory Response, Graham and Trotman, London.

Ronen, T. and D. Weaver, 2001, “Teenies Anyone?,” Journal of Financial Markets, v4, 231260.

Swan, Peter L. and Joakim Westerholm, 2004, "The Impact of Market Architectural and Institutional Features on World Equity Market Performance," Working paper, University of New South Wales and University of Sydney.

Stoll, Hans R., 1978, “The Supply of Dealer Services in Securities Markets," The Journal of Finance, v33, 1133-1151.

Stoll, Hans R., 1989, "Inferring the Components of the Bid-Ask Spread: Theory and Empirical Tests," The Journal of Finance, v44, 115-134.

Stoll, Hans R., 2000, “Friction,” The Journal of Finance, v55(4), 1479-1514.

Tinic, S. M. and R. R.West, 1974, "Marketability of common stocks in Canada and the USA : A comparison of agent versus dealer dominated markets," The Journal of Finance, v29(3), 729-746.

Venkataraman, Kumar, 2001, “Automated Versus Floor Trading: an Analysis of Execution Costs on the Paris and New York Exchanges," The Journal of Finance, v56(4), 14451485 .

White, Halbert, 1980, “A Heteroskedasticity-Consistent Covariance Matrix Estimator and a Direct Test for Heteroskedasticity," Econometrica, v48(4), 817-838. 
Table 1

Description of NSC (Euronext Paris) and SETS (LSE)

\begin{tabular}{|c|c|c|}
\hline Organisational feature & NSC (Euronext Paris) & SETS (LSE) \\
\hline Trading mechanism & $\begin{array}{l}\text { - Automated, order-driven and continuous } \\
\text { market system } \\
\text { - Automated, order-driven and batch } \\
\text { auctions for smaller companies }\end{array}$ & $\begin{array}{l}\text { - Automated, order-driven and continuous } \\
\text { market system for Blue Chips }\end{array}$ \\
\hline Liquidity providers & $\begin{array}{l}\text { - Patient investors (limit orders) } \\
\text { - « Liquidity providers » provide liquidity } \\
\text { for small and mid caps in the order book }\end{array}$ & $\begin{array}{l}\text { - Patient investors (limit orders) } \\
\text { - RSPs for retail orders, and broker-dealers } \\
\text { outside the order book }\end{array}$ \\
\hline Most frequent types of orders & $\begin{array}{l}\text { - Limit orders } \\
\text { - Market orders }\end{array}$ & $\begin{array}{l}\text {-Limit orders } \\
\text {-Market orders } \\
\text {-At best orders } \\
\end{array}$ \\
\hline Priority rules & $\begin{array}{l}\text { Price } \\
\text { - Time }\end{array}$ & $\begin{array}{l}\text { - Price } \\
\text { - Time }\end{array}$ \\
\hline $\begin{array}{l}\text { Trading mechanism for } \\
\text { ordinary trades }\end{array}$ & $\begin{array}{l}\text { Matching of orders in the electronic order } \\
\text { book }\end{array}$ & $\begin{array}{l}\text { - Matching of orders in the order book for } \\
\text { Blue Chips (SETS) } \\
\text { - Bilateral negotiations with dealers off the } \\
\text { order book } \\
\text { - Processing of retail orders by RSPs, } \\
\text { generally at a price at least as favourable as } \\
\text { the order book best limit }\end{array}$ \\
\hline Block market & $\begin{array}{l}\text { Ability to process block trades at a price } \\
\text { between the volume weighted averages of } \\
\text { the five best order book bid and ask } \\
\text { quotes, with longer delay for trade } \\
\text { reporting. Available for large trades and a } \\
\text { small group of large capitalisations only. } \\
\text { Automated cross trade procedure (price } \\
\text { inside the order book best bid and ask } \\
\text { limits). }\end{array}$ & $\begin{array}{l}\text { Ability to process protected block trades, that } \\
\text { is of benefiting from a longer delay for } \\
\text { reporting the trade }\end{array}$ \\
\hline Trading day schedule & $\begin{array}{l}\text { Opening call auction at } 9.00 \text { am (Paris } \\
\text { time) } \\
\text { Continuous auction from } 9.00 \text { to } 17.30 \mathrm{pm} \\
\text { Closing call auction at } 17.35 \mathrm{pm}\end{array}$ & $\begin{array}{l}\text { Opening call auction at } 8.00 \mathrm{am} \text { (Paris time) } \\
\text { Continuous auction from } 8.00 \text { to } 16.30 \mathrm{pm} \\
\text { Closing call auction at } 16.35 \mathrm{pm}\end{array}$ \\
\hline Tick size & $\begin{array}{l}\text { - Price lower than } 50 €: 0,01 € \\
\text { - Price between } 50 \text { and } 100 €: 0,05 € \\
\text { - Price between } 100 \text { and } 500 €: 0,1 € \\
\text { - Price over } 500 €: 0,5 €\end{array}$ & $\begin{array}{l}\text {-Price lower than } 5 £: 0,25 \mathrm{p} \\
\text {-Price between } 5 \text { and } 10 £: 0,5 \mathrm{p} \\
\text {-Price over } 10 £: 1 \mathrm{p}\end{array}$ \\
\hline
\end{tabular}


Table 2

Descriptive statistics on volatility, spreads and trading characteristics

\begin{tabular}{|c|c|c|c|}
\hline \multirow{2}{*}{ Trading mechanism } & \multirow{2}{*}{ NSC } & \multicolumn{2}{|c|}{ SETS } \\
\hline & & In the order book & Off the order book \\
\hline Total trading volume $(€)$ & $480,611,170,097$ & $\begin{array}{c}201,153,418,863 \\
(44.41 \%)\end{array}$ & $\begin{array}{c}361,888,482,178 \\
(55.59 \%)\end{array}$ \\
\hline Volatility (\%) & $\begin{array}{c}2.4709 \\
(0.1006) \\
{[2.349]}\end{array}$ & & \\
\hline Quoted spread (\%) & $\begin{array}{c}0.2595 \\
(0.01625) \\
{[0.2177]}\end{array}$ & & \\
\hline Average number of quotes per day & $\begin{array}{c}1,803.82 \\
(181.09) \\
{[1,636.34]}\end{array}$ & & \\
\hline Effective spread (\%) & $\begin{array}{c}0.2495 \\
(0.0151) \\
{[0.2142]}\end{array}$ & $\begin{array}{c}0.4132 \\
(0.0346) \\
{[0.3278]}\end{array}$ & $\begin{array}{c}0.4897 \\
(0.0376) \\
{[0.4134]}\end{array}$ \\
\hline Effective marginal cost $(\%)$ & $\begin{array}{c}0.0710 \% \\
(0.0074 \%) \\
{[0.0619 \%]}\end{array}$ & $\begin{array}{c}0.2265 \% \\
(0.0414 \%) \\
{[0.307 \%]}\end{array}$ & $\begin{array}{c}0.2717 \% \\
(0.0404 \%) \\
{[0.183 \%]}\end{array}$ \\
\hline Average number of trades per day & $\begin{array}{c}153,020.62 \\
(10,732.18) \\
{[123,404]}\end{array}$ & $\begin{array}{c}34,412.82 \\
(3,183.68) \\
{[32,050]}\end{array}$ & $\begin{array}{c}35,055.09 \\
(5,200.51) \\
{[25,254]}\end{array}$ \\
\hline Average trade size (€) & $46,305.59$ & $63,705.33$ & $135,192.18$ \\
\hline
\end{tabular}

Statistics are computed for the first six months of 2001 for 55 pairs of securities quoted on either the French market or the British market. Call auction trades and VWAP trades were not taken into account. The trading is expressed in $€$ and relates to trade numbers during the first six months of 2001 multiplied by the respective trading prices. Average trade numbers are averages over securities of daily trade averages for the first six months of 2001. The average trade size is first semester 2001 trading volume (in $€$ ) divided by the total number of trades. For each security, quoted spreads are firstly calculated by weighting each spread by its time of duration. Finally, quoted and effective spreads are calculated as equally-weighted averages. Volatility stands for volatilities calculated on the basis of daily closing price returns. The variable was subsequently computed as a non-biased standard error of daily closing price returns. For each variable, standard error values are between brackets and medians between square brackets. All these statistics exhibit a significant difference between NSC and SETS at the $1 \%$ level. 
Table 3

Effective spreads by transaction class

NSC

SETS

Trade class

\begin{tabular}{cccccc}
\hline $\begin{array}{c}\text { Effective } \\
\text { volume } \\
\text { volume }\end{array}$ & $\%$ trades & $\begin{array}{c}\text { \% Trading } \\
\text { volume }\end{array}$ & $\%$ trades & $\begin{array}{c}\text { Effective } \\
\text { spreads (\%) }\end{array}$
\end{tabular}

\begin{tabular}{|c|c|c|c|c|c|c|c|c|}
\hline \multirow{3}{*}{ All classes } & All & $100 \%$ & $100 \%$ & 0.2495 & $100 \%$ & $100 \%$ & 0.4446 & 5.17 \\
\hline & iob & --- & --- & --- & $44.42 \%$ & $49.51 \%$ & 0.4132 & 4.45 \\
\hline & oob & --- & --- & --- & $55.58 \%$ & $50.49 \%$ & 0.4897 & --- \\
\hline \multirow{3}{*}{$\begin{array}{c}\text { Class } 1 \\
<5\end{array}$} & All & $1.26 \%$ & $34.62 \%$ & 0.2525 & $0.76 \%$ & $29.88 \%$ & 0.4423 & 4.89 \\
\hline & iob & --- & --- & --- & $0.19 \%$ & $7.53 \%$ & 0.4103 & 4.32 \\
\hline & oob & --- & --- & --- & $0.57 \%$ & $22.35 \%$ & 0.457 & \\
\hline \multirow{3}{*}{$\begin{array}{c}\text { Class } 2 \\
5-20\end{array}$} & All & $5.01 \%$ & $27.25 \%$ & 0.246 & $3.39 \%$ & $29.47 \%$ & 0.4269 & 4.80 \\
\hline & iob & --- & --- & --- & $1.55 \%$ & $12.98 \%$ & 0.4038 & 4.32 \\
\hline & oob & --- & --- & --- & $1.74 \%$ & $16.5 \%$ & 0.5025 & --- \\
\hline \multirow{3}{*}{$\begin{array}{c}\text { Class } 3 \\
20-60\end{array}$} & All & $11.58 \%$ & $18.42 \%$ & 0.2473 & $6.33 \%$ & $16.82 \%$ & 0.4333 & 4.87 \\
\hline & iob & --- & --- & --- & $4.64 \%$ & $12.1 \%$ & 0.4108 & 4.42 \\
\hline & oob & --- & --- & --- & $1.69 \%$ & $4.72 \%$ & 0.5557 & --- \\
\hline \multirow{3}{*}{$\begin{array}{c}\text { Class } 4 \\
60-100\end{array}$} & All & $10.11 \%$ & $7.47 \%$ & 0.2549 & $5.37 \%$ & $6.54 \%$ & 0.4455 & 4.71 \\
\hline & iob & --- & --- & --- & $4.25 \%$ & $5.21 \%$ & 0.4147 & 4.29 \\
\hline & oob & --- & --- & --- & $1.08 \%$ & $1.32 \%$ & 0.5736 & \\
\hline \multirow{3}{*}{$\begin{array}{c}\text { Class } 5 \\
100-250\end{array}$} & All & $22.16 \%$ & $8.17 \%$ & 0.2698 & $15.97 \%$ & $9.46 \%$ & 0.4692 & 4.64 \\
\hline & iob & --- & --- & --- & $12.41 \%$ & $7.4 \%$ & 0.4199 & 3.97 \\
\hline & oob & --- & --- & --- & $3.55 \%$ & $2.07 \%$ & 0.6069 & --- \\
\hline \multirow{3}{*}{$\begin{array}{c}\text { Class } 6 \\
250-500\end{array}$} & All & $16.6 \%$ & $2.77 \%$ & 0.2821 & $16.34 \%$ & $4.44 \%$ & 0.5407 & 5.03 \\
\hline & iob & --- & --- & --- & $11.22 \%$ & $3.08 \%$ & 0.4386 & 4.09 \\
\hline & oob & --- & --- & --- & $5.13 \%$ & $1.36 \%$ & 0.6069 & --- \\
\hline \multirow{3}{*}{$\begin{array}{c}\text { Class } 7 \\
500-1,000\end{array}$} & All & $10.95 \%$ & $0.92 \%$ & 0.2785 & $14.52 \%$ & $2.01 \%$ & 0.6686 & 6.07 \\
\hline & iob & --- & --- & --- & $7.02 \%$ & $1 \%$ & 0.4704 & 3.05 \\
\hline & oob & --- & --- & --- & $7.5 \%$ & $1.01 \%$ & 0.7046 & --- \\
\hline \multirow{3}{*}{$\begin{array}{c}\text { Class 8 } \\
1,000-2,500\end{array}$} & All & $7.3 \%$ & $0.25 \%$ & 0.2727 & $15.69 \%$ & $0.99 \%$ & 0.7481 & 5.66 \\
\hline & iob & --- & --- & --- & $2.83 \%$ & $0.2 \%$ & 0.4622 & 2.86 \\
\hline & oob & --- & --- & --- & $12.86 \%$ & $0.79 \%$ & 0.7571 & --- \\
\hline \multirow{3}{*}{$\begin{array}{r}\text { Class } 9 \\
>2,500\end{array}$} & All & $15.04 \%$ & $0.1 \%$ & 0.3371 & $21.73 \%$ & $0.39 \%$ & 0.9581 & 4.94 \\
\hline & iob & --- & --- & --- & $0.26 \%$ & $0.01 \%$ & 0.3435 & 0.06 \\
\hline & oob & --- & --- & --- & $21.47 \%$ & $0.38 \%$ & 0.9591 & --- \\
\hline
\end{tabular}

This table reports the means of effective spreads on Euronext Paris and SETS for two paired samples of 55 securities. The effective spread is classified by class of transaction and by distinguishing order book trades from other trades. Average spreads are calculated as averages equally-weighted. Sizes defining the transaction classes are given in thousand euros in the first column. For the LSE, the sample has been divided into two groups, according to the fact that transactions may be made through the order book on SETS, outside the order book. "iob" stands for in order book and "oob" stands for "off order book". The statistic T corresponds to the two-sample t-test in order to compare the difference between Euronext and SETS. Figures in bold mean that the difference is significant at the $5 \%$ threshold at least. 


\section{Table 4}

Components of the bid-ask spread on NSC and SETS

Huang and Stoll' (1997) two-way decomposition model

\begin{tabular}{|c|c|c|c|c|c|}
\hline \multirow{2}{*}{ Market } & \multicolumn{5}{|c|}{ Adverse selection and inventory holding cost component $\lambda$} \\
\hline & Mean & Std. Err. & Median & $\mathbf{T}$ & $\mathbf{S}$ \\
\hline SETS (all trades) & $17.59 \%$ & 0.1075 & 0.1601 & & \\
\hline $\begin{array}{l}\text { SETS } \\
\text { (in-order-book trades only) }\end{array}$ & $44.53 \%$ & 0.0151 & 0.4459 & & \\
\hline NSC & $38.16 \%$ & 0.0097 & 0.3655 & & \\
\hline$\lambda_{S E T S}-\lambda_{N S C}$ & $-20.57 \%$ & 0.0139 & -0.2051 & $-14.76^{* * *}$ & $-3.37 * * *(52<0)$ \\
\hline$\lambda_{S E T S \_i o b}-\lambda_{N S C}$ & $6.36 \%$ & 0.0163 & 0.0634 & $3.9 * * *$ & $1.82 *(37>0)$ \\
\hline
\end{tabular}

This table presents the results obtained from a two-way decomposition of the spread following Huang and Stoll's model. $\lambda$ is the proportion of traded spread due to adverse selection and inventory holding cost, the order processing cost being $1-\lambda$. The last two rows present the differences in $\lambda$ and the associated parametric tests of inter-market differences. The statistics $\mathrm{T}$ and $\mathrm{S}$ correspond respectively to the two-sample t-test and the two-sample sign test to compare the difference between NSC and SETS. The figures into brackets show the number of pairs for which the difference is either positive or negative. 


\section{Table 5}

Components of the bid-ask spread on SETS and NSC - Huang and Stoll' (1997) three-way decomposition model

\begin{tabular}{|c|c|c|c|c|c|c|c|c|c|c|c|c|c|}
\hline \multirow{2}{*}{ Market } & \multirow{2}{*}{$\begin{array}{l}\text { Nb of } \\
\text { stocks }\end{array}$} & \multicolumn{4}{|c|}{$\pi$} & \multicolumn{4}{|c|}{$\alpha$} & \multicolumn{4}{|c|}{$\beta$} \\
\hline & & Mean & Std. Err. & Median & $\begin{array}{c}\mathrm{Nb} \text { of stocks } \\
\text { with } \pi>0.5\end{array}$ & Mean & Std. Err. & Median & $\begin{array}{c}\mathrm{Nb} \text { of stocks } \\
\text { with } \alpha>0\end{array}$ & Mean & Std. Err. & Median & $\begin{array}{c}\mathrm{Nb} \text { of stocks } \\
\text { with } \beta>0\end{array}$ \\
\hline $\begin{array}{l}\text { SETS } \\
\text { (all trades) }\end{array}$ & 18 & 0.4134 & 0.0154 & 0.4296 & 0 & 0.0582 & 0.0114 & 0.0486 & 8 & 0.1152 & 0.0173 & 0.1167 & 11 \\
\hline $\begin{array}{l}\text { SETS } \\
\text { (in-order-book } \\
\text { trades only) }\end{array}$ & 44 & 0.4214 & 0.0049 & 0.4274 & 0 & 0.286 & 0.0265 & 0.2573 & 31 & 0.2557 & 0.0202 & 0.261 & 28 \\
\hline NSC & 25 & 0.5148 & 0.0189 & 0.5387 & 14 & 0.0924 & 0.0139 & 0.0807 & 14 & 0.1743 & 0.12 & 0.184 & 22 \\
\hline
\end{tabular}

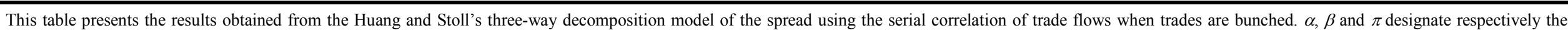

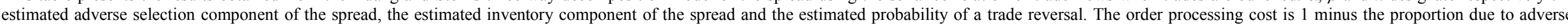

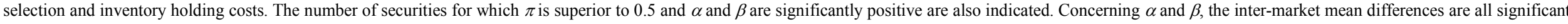
at the $1 \%$ level except for the $\alpha$ difference between SETS (all trades) and NSC (significant at the $10 \%$ level). 
Table 6

Components of the bid-ask spread on SETS and NSC - Huang and Stoll' (1997) three-way decomposition model - Stock pairs estimates

\begin{tabular}{|c|c|c|c|c|c|c|c|c|c|c|}
\hline SETS firm & NSC firm & $\pi_{N S C}$ & $\pi_{\text {SETS }}$ & $\pi_{\text {SETS-iob }}$ & $\alpha_{N S C}$ & $\alpha_{S E T S}$ & $\alpha_{S E T S-i o b}$ & $\beta_{N S C}$ & $\beta_{\text {SETS }}$ & $\beta_{\text {SETS-iob }}$ \\
\hline Aegis Group & $\begin{array}{l}\text { Groupe } \\
\text { Publicis }\end{array}$ & 0.4084 & 0.4067 & 0.3995 & $3.03 \%$ & $2.14 \%$ & $23.09 \%$ & $17.56 \%$ & $15.59 \%$ & $32.27 \%$ \\
\hline $\begin{array}{l}\text { National Grid } \\
\text { Group }\end{array}$ & $\begin{array}{l}\text { Suez } \\
\text { Lyonnaise des } \\
\text { Eaux }\end{array}$ & 0.5387 & 0.4436 & 0.4279 & $29.13 \%$ & $6.61 \%$ & $37.77 \%$ & $0.3 \%$ & $17.72 \%$ & $15.11 \%$ \\
\hline Pilkington plc & Legrand ord. & 0.426 & 0.4171 & 0.3897 & $7.38 \%$ & $2.69 \%$ & $30.23 \%$ & $21.46 \%$ & $4.5 \%$ & $39.71 \%$ \\
\hline Pearson plc & LVMH & 0.5577 & 0.4672 & 0.4497 & $7.8 \%$ & $14.72 \%$ & $17.25 \%$ & $18.4 \%$ & $3.75 \%$ & $27.75 \%$ \\
\hline Halifax & $\begin{array}{l}\text { Société } \\
\text { Générale }\end{array}$ & 0.5935 & 0.1713 & 0.438 & $11.92 \%$ & $0.45 \%$ & $29.91 \%$ & $15.42 \%$ & $3.99 \%$ & $26.41 \%$ \\
\hline $\begin{array}{l}\text { Great } \\
\text { Universal } \\
\text { Stores plc }\end{array}$ & Renault & 0.5699 & 0.4372 & 0.4229 & $9.23 \%$ & $2 \%$ & $24.25 \%$ & $15.16 \%$ & $23.45 \%$ & $34.22 \%$ \\
\hline $\begin{array}{l}\text { Enterprise Oil } \\
\text { plc }\end{array}$ & Coflexip & 0.3785 & 0.4412 & 0.4301 & $4.48 \%$ & $3.52 \%$ & $24.14 \%$ & $28.73 \%$ & $16.21 \%$ & $31.06 \%$ \\
\hline
\end{tabular}

This table presents the results obtained from the Huang and Stoll's three-way decomposition model of the spread using the serial correlation of trade flows when trades are bunched. The components are estimated on the basis of serial correlation in trade flows with bunching. $\alpha, \beta$ and $\pi$ designate respectively the estimated adverse selection component of the spread, the estimated inventory component of the spread and the estimated probability of a trade reversal. The order processing cost is 1 minus the proportion due to adverse selection and inventory holding cost. 
Table 7

Cross-sectional regressions of the differential spreads between SETS and NSC

\begin{tabular}{|c|c|c|c|c|c|c|c|c|c|}
\hline Variable & $\Delta a q s$ & $\Delta a q s$ & $\Delta a q s$ & $\Delta a e s$ & $\Delta a e s$ & $\Delta a e s$ & $\Delta w e s$ & $\Delta w e s$ & $\Delta w e s$ \\
\hline Intercept & $\begin{array}{c}0.3101^{* * * *} \\
{[6.78]}\end{array}$ & & & $\begin{array}{c}0.0979 * * * \\
{[5.23]}\end{array}$ & & & $\begin{array}{c}0.2027 * * * \\
{[6.92]}\end{array}$ & & \\
\hline$\Delta \sigma$ & $\begin{array}{c}0.1146^{* * * *} \\
\quad[8.15]\end{array}$ & $\begin{array}{c}0.1352 * * * \\
\quad[9.58]\end{array}$ & $\begin{array}{c}0.1061 * * * \\
{[7.86]}\end{array}$ & $\begin{array}{c}0.0736^{* * * *} \\
{[12.78]}\end{array}$ & $\begin{array}{c}0.0802 * * * \\
\quad[14.1]\end{array}$ & $\begin{array}{c}0.0703 * * * \\
{[12.58]}\end{array}$ & $\begin{array}{c}0.0972 * * * \\
{[10.79]}\end{array}$ & $\begin{array}{c}0.1107 * * * \\
{[12.22]}\end{array}$ & $\begin{array}{c}0.0943 * * * \\
{[10.66]}\end{array}$ \\
\hline$\Delta \ln V$ & $\begin{array}{c}-0.0973^{* *} \\
{[-2.16]}\end{array}$ & $\begin{array}{c}-0.0106 \\
{[-0.24]}\end{array}$ & $\begin{array}{c}-0.146^{* * * *} \\
{[-3.33]}\end{array}$ & $\begin{array}{c}-0.0634 * * * \\
{[-3.44]}\end{array}$ & $\begin{array}{c}-0.0356^{* *} \\
{[-2.01]}\end{array}$ & $\begin{array}{c}-0.0818^{* * *} \\
{[-4.51]}\end{array}$ & $\begin{array}{c}-0.0649^{* *} \\
{[-2.25]}\end{array}$ & $\begin{array}{c}-0.0082 \\
{[-0.29]}\end{array}$ & $\begin{array}{c}-0.0844 * * * \\
{[-2.93]}\end{array}$ \\
\hline$\Delta \ln F M V$ & $\begin{array}{c}0.0733 * \\
{[1.72]}\end{array}$ & $\begin{array}{l}0.0726 \\
{[1.63]}\end{array}$ & $\begin{array}{c}0.067 \\
{[1.64]}\end{array}$ & $\begin{array}{l}0.0057 \\
{[0.33]}\end{array}$ & $\begin{array}{c}0.0054 \\
{[0.3]}\end{array}$ & $\begin{array}{c}0.0038 \\
{[0.22]}\end{array}$ & $\begin{array}{l}-0.0183 \\
{[-0.67]}\end{array}$ & $\begin{array}{c}-0.0188 \\
{[-0.66]}\end{array}$ & $\begin{array}{c}-0.0226 \\
{[-0.84]}\end{array}$ \\
\hline$\Delta \ln P$ & & $\begin{array}{c}-0.0602 * * * \\
{[-4.02]}\end{array}$ & & & $\begin{array}{c}-0.0185 * * * \\
{[-3.06]}\end{array}$ & & & $\begin{array}{c}-0.0393 * * * \\
{[-4.09]}\end{array}$ & \\
\hline$\Delta \ln N$ & $\begin{array}{c}-0.0321 \\
{[-0.61]}\end{array}$ & $\begin{array}{c}-0.2241 * * * \\
{[-5.56]}\end{array}$ & $\begin{array}{l}0.0381 \\
{[0.76]}\end{array}$ & $\begin{array}{l}-0.0121 \\
{[-0.56]}\end{array}$ & $\begin{array}{c}-0.0736^{* * *} \\
{[-4.54]}\end{array}$ & $\begin{array}{l}0.016 \\
{[0.77]}\end{array}$ & $\begin{array}{l}-0.0276 \\
{[-0.82]}\end{array}$ & $\begin{array}{c}-0.1532 * * * \\
{[-5.92]}\end{array}$ & $\begin{array}{c}-0.0056 \\
{[-0.17]}\end{array}$ \\
\hline$\Delta \ln I$ & $\begin{array}{c}0.0115^{* * * *} \\
\quad[3.41]\end{array}$ & $\begin{array}{c}0.0071^{* *} \\
{[2.07]}\end{array}$ & $\begin{array}{c}0.0097 * * * \\
{[3.07]}\end{array}$ & $\begin{array}{c}0.0047 * * * \\
\quad[3.37]\end{array}$ & $\begin{array}{c}0.0032 * * \\
{[2.35]}\end{array}$ & $\begin{array}{c}0.0041 * * * \\
\quad[3.17]\end{array}$ & $\begin{array}{l}0.004^{*} \\
{[1.85]}\end{array}$ & $\begin{array}{c}0.0011 \\
{[0.5]}\end{array}$ & $\begin{array}{l}0.0025 \\
{[1.22]}\end{array}$ \\
\hline$\Delta t i c k$ & $\begin{array}{c}0.9941^{* * * *} \\
{[3.19]}\end{array}$ & $\begin{array}{c}0.962 * * * \\
{[2.69]}\end{array}$ & $\begin{array}{c}0.631 * * \\
{[2.06]}\end{array}$ & $\begin{array}{c}0.9479 * * * \\
{[7.43]}\end{array}$ & $\begin{array}{c}0.9444^{* * * *} \\
{[6.56]}\end{array}$ & $\begin{array}{c}0.8161^{* * * *} \\
{[6.45]}\end{array}$ & $\begin{array}{c}1.2765^{* * * *} \\
{[6.39]}\end{array}$ & $\begin{array}{c}1.256^{* * * *} \\
{[5.48]}\end{array}$ & $\begin{array}{c}1.1095 \\
{[5.53]^{* * *}}\end{array}$ \\
\hline$F R$ & & & $\begin{array}{c}0.6415^{* * * *} \\
{[8.87]}\end{array}$ & & & $\begin{array}{c}0.2129 * * * \\
{[7.12]}\end{array}$ & & & $\begin{array}{c}0.3771 * * * \\
{[7.97]}\end{array}$ \\
\hline Adj $R^{2}$ & 0.633 & 0.601 & 0.663 & 0.725 & 0.704 & 0.737 & 0.727 & 0.702 & 0.738 \\
\hline
\end{tabular}

This table presents the cross-sectional regression model to explain the difference of effective spreads between NSC and SETS for 55 pairs of firms during the first semester of 2001. Observations are monthly for each pair, which results in a sample of $330(55 \times 6)$ observations. The dependant variable is either the difference of average quoted spreads, either of average effective spreads or of average weighted spreads. The least squares regression models are developed, using hypothesis tests based on consistent estimates of covariance matrices allowing for heteroskedasticity, as in White (1980). $*, * * * * *$ denote significance of the test at the $10 \%, 5 \%$ and $1 \%$ levels respectively: t-statistics are in square brackets. 